\title{
PALEOPATOLOGÍA Y ESTILO DE VIDA: EL EJEMPLO DE LOS CHONOS
}

\author{
EUGENIO ASPILLAGA F. ${ }^{*}$, MARIO CASTRO D. ${ }^{*}$, MÓNICA RODRÍGUEZ ${ }^{* *}$ y CARLOS OCAMPO E. ${ }^{* * *}$
}

\section{RESUMEN}

La historia de los pueblos aborígenes del extremo sur de Sudamérica se caracteriza por el poblamiento de dos grandes grupos culturales: los cazadores terrestres y los canoeros. No obstante estas poblaciones habitaron ambientes contrastantes, ellas desarrollaron contactos en varias zonas, produciéndose como resultado un rico intercambio cultural y biológico. Directa e indirectamente, el proceso colonizador europeo tuvo como consecuencia la rápida extinción de estos grupos aborígenes. El presente trabajo evalúa los cambios patológicos en restos óseos de indígenas Chonos en comparación con aquellos observados en grupos Fueguinos. La muestra esta compuesta por aproximadamente 96 individuos Chonos y 38 Fueguinos. Los resultados señalan una fuerte correlación entre morbilidad y factores asociados al estilo de vida cazador-recolector, es decir, gran estrés físico, deficiencias nutricionales, etc. Los restos de Chonos exhiben una elevada prevalencia de enfermedades infecciosas y lesiones osteoarticulares. Estas y otras condiciones patológicas tienden a caracterizar a esta etnia como un grupo en crisis -biológica y cultural- al momento del contacto con los europeos.

PALABRAS CLAVES: chonos, paleopatología, estilo de vida.

PALAEOPATHOLOGY AND LIFE-STYLE: THE CHONOAN EXAMPLE

\section{ABSTRACT}

The history of the aboriginal peoples of the southern tip of South America is characterized by the cultural development of two major groups: terrestrial hunters and canoe indians. Although these groups lived in contrasting environments they had contact in various zones, thus enjoying a rich cultural and biological exchange. The European colonization process brought about, directly and indirectly, the rapid extinction of these populations. This study evaluates pathological changes in skeletons of Chono Indians as compared to those observed in Fuegian groups. The sample consists of approximately 96 Chono individuals and 38 Fuegians. The study results show a strong correlation between morbidity and factors related to the hunting and gathering way of life, i.e., great physical stress, nutritional deficiency, etc. The $C$ hono remains show a high prevalence of infectious diseases together with a number of osteoarticular disorders. These and other pathological conditions tend to characterize the Chono as a group in crisis -in a biological and cultural sense- at the time of the contact with the Europeans.

KEY WORDS: chonoan, paleopathology, life-style.

* Departamento de Antropología, Facultad de Ciencias Sociales, Universidad de Chile. Avda. Ignacio Carrera Pinto 1045, Santiago.

** Subdirección de Museos, Dirección de Bibliotecas, Archivos y Museos (DIBAM). Clasificador 1400, Santiago.

*** Ciprés Consultores, Siuox 2075, Santiago. 


\section{INTRODUCCIÓN}

En las poblaciones prehispánicas de Chile, una parte significativa de la evidencia paleopatológica proviene de los restos óseos arqueológicos. Sin embargo, el conocimiento sobre la biología del grupo Chono es tan fragmentario como la información disponible respecto de su cultura.

El análisis paleopatológico permite clarificar el impacto biológico y cultural de las enfermedades en las poblaciones humanas (Ortner 1992). Considerando que los patógenos evolucionan de igual manera que las poblaciones huéspedes, es de importante valor biomédico como también antropológico conocer las condiciones de salud de los grupos humanos antiguos, especialmente de aquellos extintos (Ubelaker 1998; Mendonca de Souza et al. 2003). El caso de los Chonos es un buen ejemplo de ello, y los restos que se describen en este trabajo corresponden a las primeras evidencias bioantropológicas documentadas sobre esta etnia. Este grupo, que desaparece con posterioridad a la colonización española de Chiloé, venía en una decadencia demográfica cuya explicación todavía no está clara. Más aún, existe un pobre registro arqueológico de sus bienes culturales.

Esta investigación describe las condiciones paleopatológicas observadas en un conjunto de restos óseos Chonos, comparándolas con las de otros grupos aborígenes del extremo sur, y busca establecer la etiología de algunas de las lesiones así como sus implicancias culturales en la población. Una versión resumida de este trabajo fue presentada en la 59 Reunión Anual de la Asociación Americana de Antropología Física, en el año 1990 (Aspillaga et al. 1990).

\section{ANTECEDENTES HISTÓRICOSY ANTROPOLÓGICOS}

Los Chonos eran aborígenes canoeros que ocuparon una franja de territorio de unos 500 kilómetros de longitud en la Patagonia Occidental Insular Septentrional, entre las islas Guaitecas y la península de Taitao y el golfo de Penas e islas Guayanecos (Cooper 1917), aunque también parecen haber ocupado la parte sur del archipiélago de Chiloé (Fig. 1). Su habitat corresponde a una región de escarpadas islas, fiordos profundos y canales sinuosos, con un clima templado frío con máxima invernal de lluvias caracterizado por la prevalencia de días nublados y húmedos, elevada

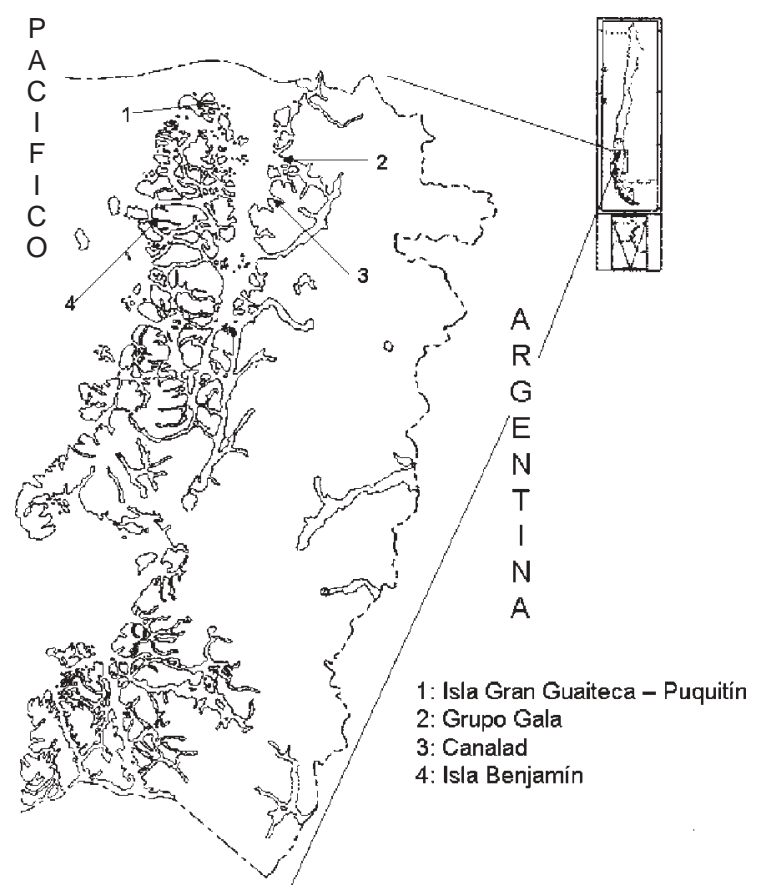

Fig. 1. Mapa general de la Región de Aysén.

pluviosidad durante todo el año (hasta $4.000 \mathrm{~mm}$ anuales), fuertes vientos occidentales y temperaturas frías (Romero 1985). Ello se refleja en la predominancia de especies vegetales como el coigüe, el ciprés de las Guaitecas, el coigüe de Chiloé, la lenga, el alerce, el laurel, el canelo, la luma, el arrayán, el mañío y los helechos. Además, la fauna esta compuesta por especies diversas, donde destacan la nutria, el pudú, el huemul y algunos marsupiales como el monito del monte, junto a una gran variedad de aves y mamíferos marinos (Quintanilla 1983).

N umerosos relatos sobre el territorio Chono señalan una baja densidad demográfica, sin embargo no existen datos exactos sobre la población total. Los Chonos estaban en contacto con los Chilotes así como con los Alacalufes (Cooper 1917; Butland 1957; Quiroz y Olivares 1988).

El conocimiento de que disponemos de la cultura Chono es muy limitado. La mayor parte de la información proviene de viajeros y exploradores que tuvieron algún contacto con ellos (Quiroz y Olivares 1988). En muchos aspectos, sus estrategias de subsistencia eran similares a las de los Alacalufes (pescadores y cazadores/recolectores marinos). El pescado, los mariscos y la carne de lobo marino conformaron su dieta básica. Su vi- 
vienda estaba construida de varillas cubiertas con ramas, corteza o pieles. El transporte era casi exclusivamente por agua y para ello empleaban canoas de corteza o de tablas (dalca). Las armas usuales de caza eran el arpón de pesca y palos (Quiroz y Olivares 1988; Urbina 1988).

Los Chonos vivían en familias extensas deambulando por los canales. La división del trabajo se basaba en el género, donde la recolección de mariscos era tarea femenina mientras que el mantenimiento del fuego y la caza de mamíferos marinos y aves eran actividades de los hombres (Urbina 1988). Por otra parte, disponían de algún tipo de organización jerárquica tribal pero se desconoce que autoridad poseían los "jefes" (Cooper 1917, 1946).

El patrón funerario atribuido a los Chonos se basa en el relato del inglés J ohn Byron, quién en 1768 describe el hallazgo de varios cuerpos de individuos fallecidos en la profundidad de una caverna y dispuestos en dos niveles, unos sobre un andas hecha de palos entrecruzados que descansaba en puntales de aproximadamente $150 \mathrm{~cm}$ de altura y otros depositados bajo esta estructura. Señala además Byron que estos restos estaban desnudos y aparentemente sin descomponer, ya que los tejidos mostraban resequedad y endurecimiento (Bulkeley y Byron, 2004).
En 1608 arriban en la zona misioneros jesuitas y para 1617 se funda una misión en la isla de Chiloé. Entre 1611 y 1613, estos misioneros reportan la presencia de unos 220 Chonos en la región de las islas Guaitecas (Cooper 1917; Quiroz y O livares 1988). Un siglo después, unas 30 familias y un poco más tarde, unas 200 familias o algo más de 500 individuos, son reubicados bajo la tuición de los misioneros jesuitas en la isla de Huar y otras dos islas situadas en el seno del Reloncaví. Este evento marca el inicio de la extinción de los Chonos y para 1875, su rastro se pierde completamente. EI mestizaje de los Chonos con los grupos mapuches del norte, debido a su relocalización, es probablemente la razón principal de su desaparición (Quiroz y Olivares 1988; Urbina 1988).

\section{MATERIALES Y MÉTODOS}

Los restos óseos aquí descritos, fueron recuperados por un equipo de arqueólogos y antropólogos de la Universidad de Chile, liderados por Eugenio Aspillaga y Carlos O campo, entre los años 1985 y 1989, desde dos localidades geográficas separadas por el canal Moraleda: el núcleo Magdalena y el núcleo Gran Guaiteca (Fig. 2). EI núcleo Gran Guaiteca, comprende el archipiélago oceánico o islas de más afuera (con

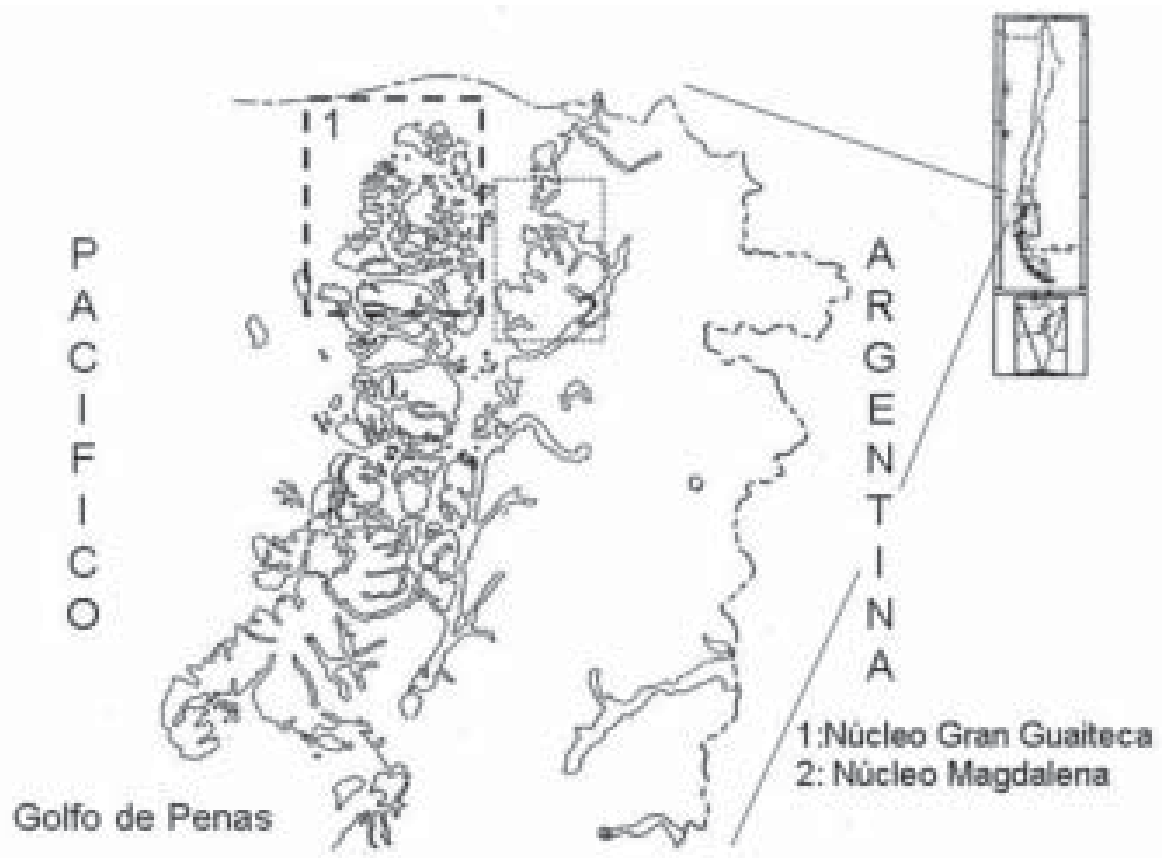

Fig. 2. Mapa que muestra la ubicación de los dos núcleos geográficos separados por el canal Moraleda. 


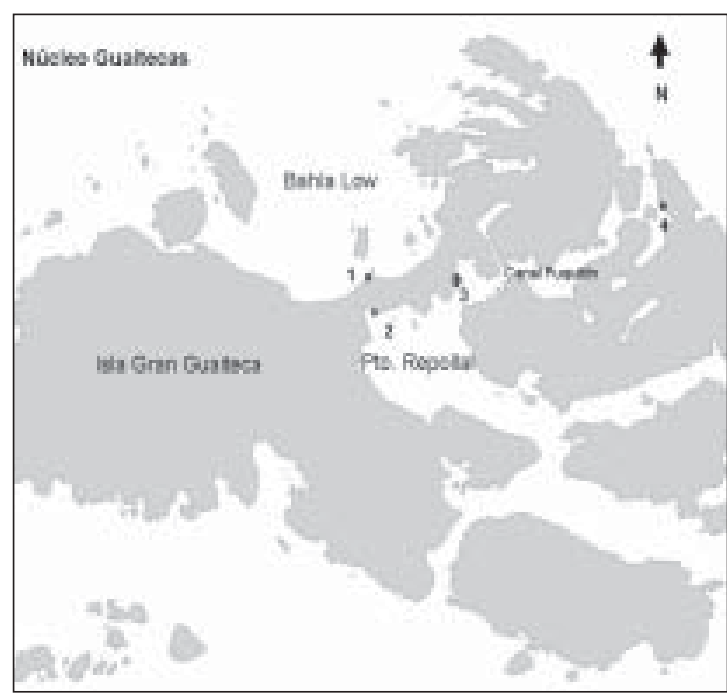

Fig. 3. Mapa del núcleo Gran Guaiteca. Se destaca la ubicación de los sitios evaluados.

relación al canal Moraleda) e incluye las islas $\mathrm{G}$ ran Guaiteca, Ascención, Clotilde y Sargento, además de bahía Low, los senos Arpones y Repollal y el canal Puquitín (Fig. 3). El núcleo Magdalena, que corresponde al borde costero continental y archipiélagos de canales interiores, considera la gran isla Magdalena junto con los sectores del canal J acaf, islas C hita y Toto, islote G emmel, entre otros (Fig. 4).

Los sitios arqueológicos fueron excavados como parte de un programa de prospección y salvataje. Para su elección se consideraron factores ecológicos y geográficos, es decir, la existencia de un gran canal (Moraleda) que redujera la probabilidad de contacto frecuente entre las poblaciones que habitaban las islas de ambos núcleos. Además, los sitios corresponden a osarios ubicados en cuevas o abrigos rocosos, los que probablemente fueron utilizados anteriormente como espacios habitacionales según se infiere de la estratigrafía. Debe señalarse que todos los restos humanos fueron encontrados en los estratos superiores de cada sitio, es decir como ocupación terminal, por lo que se asume una relativa contemporaneidad de los restos. Además, fechados radiocarbónicos del estrato superior de algunos de estos sitios indican una data de $410 \pm 70$ años AP (Ocampo y Aspillaga 1984). Por otra parte, los sitios desde donde fueron rescatados los restos poseían características similares entre sí como son aleros u oquedades rocosas y la presencia de restos de palos y corteza, estos últimos elementos descritos como parte del ajuar funerario Chono. A

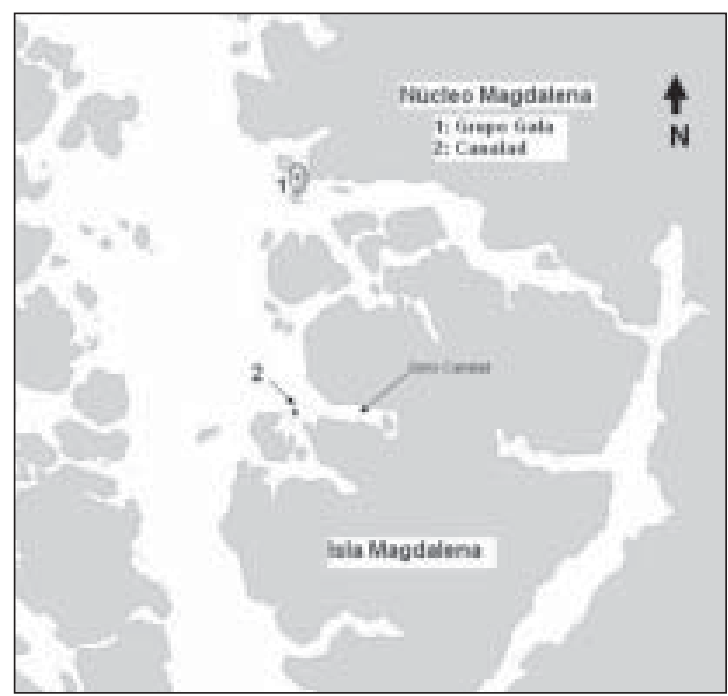

Fig. 4. Mapa del núcleo Magdalena.

Se destaca la ubicación de los sitios evaluados.

este respecto, cabe destacar que dos de los autores (E. Aspillaga y C. Ocampo) han encontrado sitios no disturbados y que permanecen sin excavar, lo que permite confirmar la existencia de una envoltura de corteza y ramas como se describe en algunos relatos para el patrón funerario de este grupo.

La determinación del número de individuos se realizó sobre la base del recuento del hueso más frecuente, en este caso las tibias. Para los sitios del núcleo Magdalena se consideró la tibia izquierda mientras que para los del núcleo Gran Guaiteca fue la tibia derecha, estableciéndose un número mínimo de individuos de 61 y 35, respectivamente. Asimismo, para propósitos comparativos, se utilizó la colección osteológica recolectada por el antropólogo Martín Gusinde y que representa a los tres grupos étnicos que poblaron el archipiélago Fueguino y canales de la Patagonia occidental: Selk'nam, Yámana, y Alacalufes (Tabla 1). Una porción significativa de esta colección, especialmente aquellos individuos atribuidos a la etnia Alacalufe/ Kawéskar, corresponde a restos históricos excavados del cementerio de la misión salesiana de isla Dawson. Si bien en muchos casos estos individuos vivieron un período largo de sus vidas confinados en la misión, buena parte de ellos ingresó a este recinto en edad adulta y por tanto sus restos esqueletales reflejan en gran medida el patrón de subsistencia cazador-recolector, a lo que se agregan las alteraciones de origen patológico inducidas por el modo de vida introducido por los misioneros..

El sexo y la edad fueron establecidos, cuan- 
TABLA 1. Distribución por sexo y edad de la Colección M. Gusinde del MNHN y de la Colección Chonos de la U. de Chile.

\begin{tabular}{|ccccc|}
\hline ETNIA/SEXO & Varones & Mujeres & Subadultos & Total \\
\hline Selk'nam & 1 & 5 & 0 & 6 \\
Yámana & 1 & 1 & 0 & 2 \\
Kawéskar & 14 & 9 & 7 & 30 \\
\hline SUBTOTAL & 16 & 15 & 7 & 38 \\
\hline $\begin{array}{c}\text { Chonos: } \\
\text { Núcleo Magdalena } \\
\text { Núcleo Gran } \\
\text { Guaiteca }\end{array}$ & 16 & 28 & 17 & 61 \\
\hline SUBTOTAL & 15 & 15 & 5 & 35 \\
\hline TOTAL & 31 & 43 & 22 & 96 \\
\hline
\end{tabular}

1 Aproximación efectuada en base a la distribución encontrada en las tibias izquierdas del osario, que arrojan un NMI de 61 individuos.

2 Aproximación efectuada en base a la distribución encontrada en las tibias derechas del osario, que arrojan un NMI de 35 individuos.

do ello fue posible, sobre la base de procedimientos bioantropológicos estándares (Bass 1987; Moore-Jansen y Jantz 1989). El examen macroscópico para evaluar rasgos indicativos de condiciones patológicas se realizó sobre la base de los protocolos de Campillo (1991) y Ortner (2003), y la evaluación del hueso temporal mediante radiología convencional, empleando para este efecto la proyección de Schüller (Castro 2002).

\section{RESULTADOS Y DISCUSIÓN}

En los Chonos, las patologías del aparato masticatorio muestran una gran prevalencia. En el núcleo Gran Guaiteca, la enfermedad periodontal esta presente en el $44 \%$ de los varones, el $54 \%$ de las mujeres y el $18 \%$ de los subadultos; mientras que en el núcleo Magdalena, el $67 \%$ de los adultos de ambos sexos la manifiesta. No obstante que los grupos Fueguinos exhiben elevadas tasas de enfermedad periodontal, su frecuencia no excede el $48 \%$ en los adultos (Tabla 2). Además, de manera semejante a los Chonos, son los cazadores-recolectores marinos los más afectados.

La enfermedad periodontal ha sido asociada a factores culturales y fisiológicos. Su presencia no puede atribuirse únicamente a deficientes prácticas de higiene oral o la presencia de alimentos abrasivos en la dieta. Algunos autores vinculan esta enfermedad a la ingesta inadecua- da de vitaminas o proteinas, así como a anemias, sífilis venérea e infecciones inespecíficas (Ortner 2003). En el caso de los Chonos, los factores nutricionales podrían ser relevantes, particularmente en lo concerniente a la deficiencia de vitamina C. Sin embargo, en la muestra Alacalufe, la enfermedad periodontal esta asociada a una dieta rica en carbohidratos con una elevada frecuencia de caries (17\%) (Castro y Aspillaga 1991).

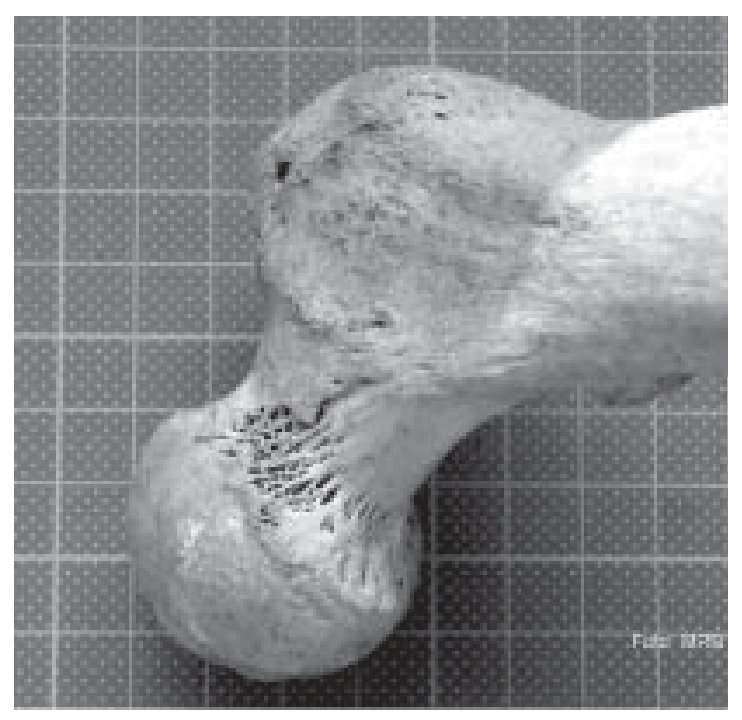

Fig. 5. Núcleo Magdalena - Gala. Fémur izquierdo de adulto de sexo femenino. Moderada criba femoral. 


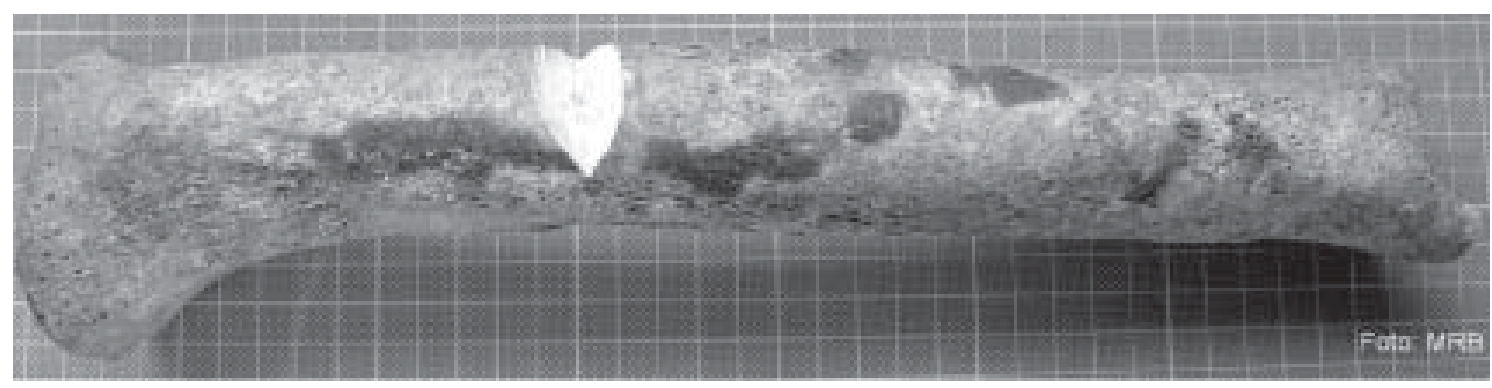

Fig. 6. Núcleo Magdalena - Gala. Tibia derecha de adulto de sexo masculino.

Abundante periostitis, vaina de sable completa. Probable treponematosis.

Debe enfatizarse que una parte importante de la colección osteológica de grupos Fueguinos corresponde a restos de individuos que estuvieron expuestos a una dieta de tipo occidental en las misiones salesianas.

En las muestras de Chonos y Selk'nam, la enfermedad periodontal esta relacionada con abcesos periodontales y lesiones osteomielíticas no vinculadas a caries, por cuanto estas últimas presentan en ambos grupos de sitios Chonos una frecuencia que no supera el $17 \%$. Sin embargo, los abcesos estan presentes en un $33 \%$ de los varones y $15 \%$ de las mujeres en el núcleo Gran Guaiteca y en un $50 \%$ y $33 \%$, respectivamente, en el núcleo Magdalena. Probablemente, estas lesiones se deben a la acción de los restos que se incrustan entre el diente y el alvéolo en una gíngiva crónicamente inflamada, facilitando así la participación de bacterias comensales en el inicio y progreso de la enfermedad (H illson 2000; Ortner 2003). Por otra parte, estudios microbiológicos de tártaro dental fosilizado en especímenes Chonos señalan que las caries podrían estar relacionadas con microorganismos

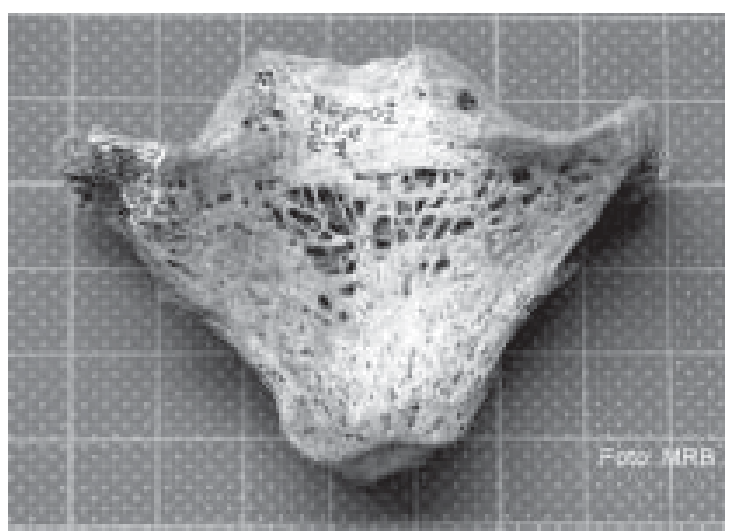

Fig. 7. Núcleo Gran Guaiteca - Repollal. Manubrio esternal de adulto de sexo masculino. Moderada actividad osteoclástica y osteoblástica que sugiere osteomielitis.
(Linossier et al. 1994). Además, el uso de la dentición como herramienta no sólo afecta al tejido gingival sino que también desgasta los dientes, causando en ocasiones su pérdida o alteraciones en la articulación témporo mandibular (Hillson 2000). Todos estos elementos parecen estar presentes en los Chonos y grupos Fueguinos.

Las lesiones traumáticas con mayor prevalencia se observan en el cráneo y la cara. En los restos de la Gran Guaiteca, los traumas craneales están presentes en el 38\% de los varones, mientras los faciales aparecen en un $23 \%$ de ellos y $22 \%$ de mujeres. En el caso del núcleo Magdalena, sólo se observan traumas craneales en un $25 \%$ de varones. Comparados con las poblaciones Fueguinas, los Chonos exhiben frecuencias más altas de lesiones de carácter traumático (Tabla 2). Una buena parte de estas lesiones pueden ser atribuidas a violencia por corresponder a traumas craneofaciales característicos, a los que se añaden otras lesiones como fracturas de ulna resultantes de la protección automática en agresiones a la cara; sin embargo, las condiciones observadas no pueden asociarse fácilmente entre sí al provenir los restos de sitios disturbados. Estas elevadas tasas indicarían que este grupo estaba expuesto a un gran estrés, lo que es consistente con otros datos paleopatológicos y la escasa evidencia etnohistórica.

Las patologías de carácter nutricional como hiperostosis porótica, criba orbitaria y criba femoral (Fig. 5) muestran elevadas frecuencias en ambos sexos y en ambos grupos. Si bien las poblaciones Fueguinas tienen prevalencias menores, debe destacarse que los restos de estas tribus son de origen histórico tardío en oposición a la mayor antigüedad del material Chono. En este último caso debe reiterarse el bajo contenido de vitamina $C$ en la dieta.

Las periostitis y osteomielitis de los huesos largos así como las lesiones articulares degenerativas, tanto de los miembros como de la 
TABLA 2. Frecuencia observada de algunas patologías en restos Chonos y Fueguinos.

\begin{tabular}{|lcc|}
\hline PATOLOGIA / ETNIA & CHONOS* & FUEGUINOS** \\
\hline Enfermedad periodontal & $58 \%$ & $48 \%$ \\
Lesiones traumáticas craneales & $32 \%$ & $16 \%$ \\
Lesiones traumáticas faciales & $22 \%$ & $16 \%$ \\
Periostitis tibiales & $52 \%$ & $13 \%$ \\
Infecciones oído medio & $64 \%$ & $64 \%$ \\
\hline
\end{tabular}

* Las frecuencias de los restos Chonos son el promedio de los dos núcleos.

** Las frecuencias de los restos Fueguinos son el promedio de los tres grupos.

columna vertebral, son las condiciones patológicas más frecuentes entre todas las patologías esqueléticas evaluadas. En el caso de la Gran Guaiteca, las periostitis tibiales están presentes en el $53 \%$ de los varones y $33 \%$ de las mujeres, mientras en el núcleo Magdalena, la frecuencia aumenta a 68 y $56 \%$, respectivamente (Fig. 6). En la mayoría de las situaciones, las lesiones involucran una porción significativa de hueso y pareciera que ellas son una respuesta a procesos infecciosos. Por contraste, los restos de Fueguinos presentan una menor tasa, pero además las periostitis están localiza- das, particularmente en la región del tobillo, lo que pudiera relacionarse con una actividad irritativa de origen traumático (Tabla 2).

Las lesiones de tipo osteomielítico se observan con mayor frecuencia en las regiones esternal (Fig. 7) y de la pierna (Fig. 8), sin una diferencia significativa entre los restos de ambos núcleos. No esta clara la etiología de estas lesiones, las cuales podrían ser causadas por diversos agentes. No se descarta entre ellos la presencia de treponematosis, infecciones como resultado de trauma e incluso derivadas de lesiones varicosas (Fig. 9). Esto últi-

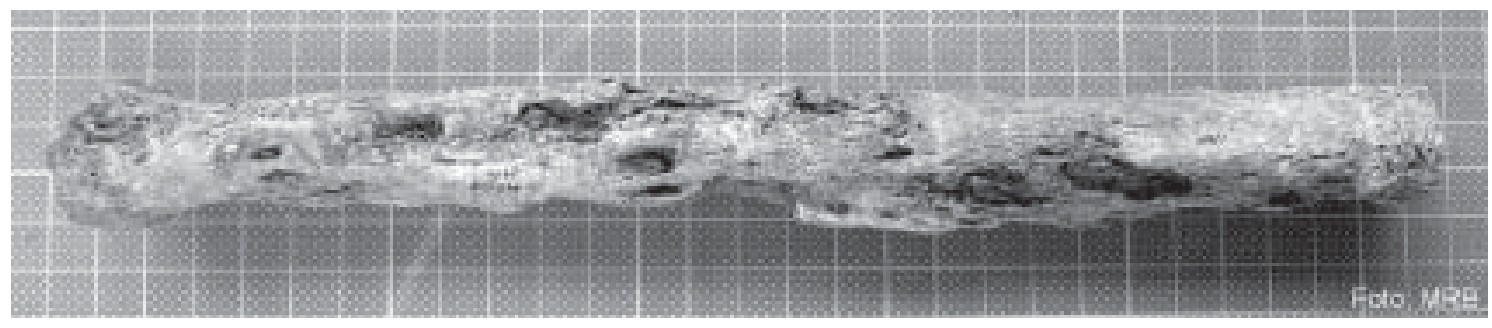

Fig. 8. Núcleo Magdalena - Gala. Fíbula izquierda de adulto de sexo masculino. Severa osteomielitis en diáfisis, con abundante periostitis, engrosamiento y formación de cistas. Vaina de sable.

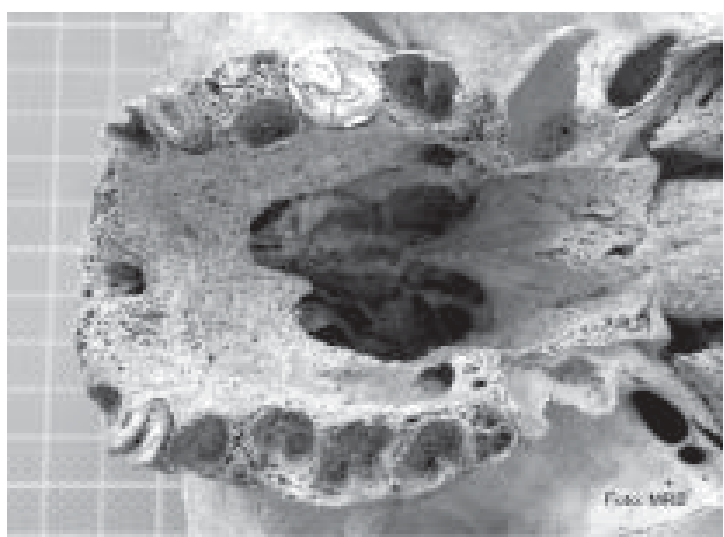

Fig. 9. Núcleo Gran Guaiteca - Repollal. Vista basal de cráneo de adulto de sexo masculino. Probable treponematosis con destrucción de los palatinos y los alvéolos de los incisivos.

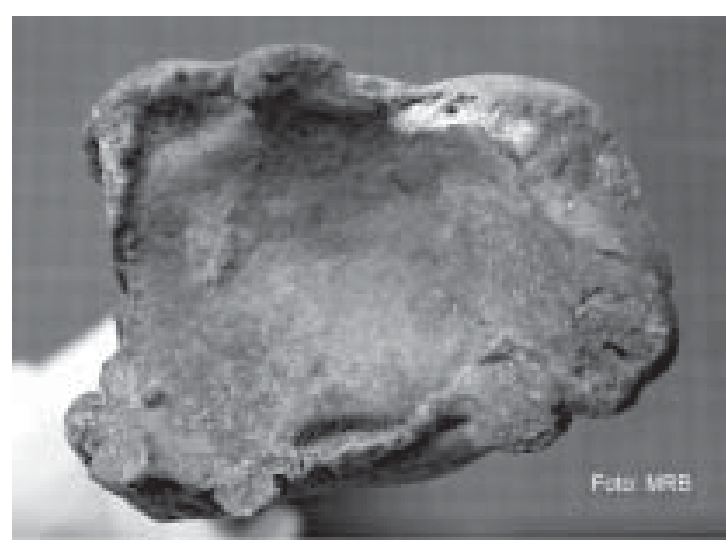

Fig. 10. Núcleo Gran Guaiteca - Repollal. Tibia izquierda de adulto de sexo masculino. Moderado lipping y espículas óseas en todo el borde de la carilla para la articulación tibiotalar. 


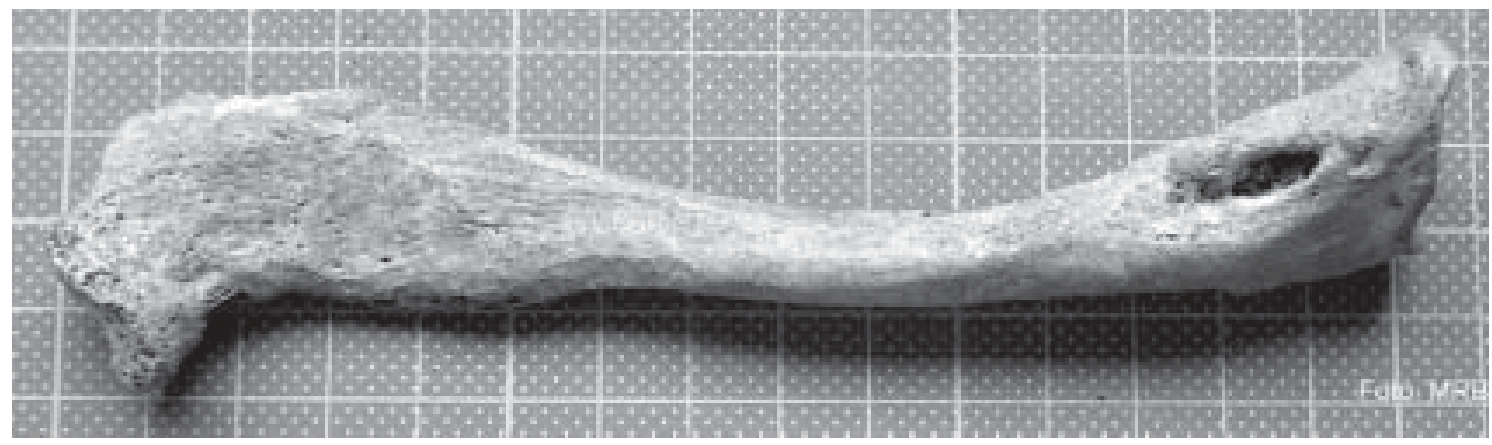

Fig. 11. Núcleo Magdalena - Gala. Clavícula izquierda de adulto de sexo masculino. Necrosis aséptica en inserción del ligamento costoclavicular. Marcadas inserciones de los músculos subclavio y trapecio, y orígenes del pectoral mayor y deltoides.

mo, podría asociarse a la descripción hecha por C. Darwin (2001) respecto de que los aborígenes canoeros presentaban grandes lesiones vasculares en sus piernas y que él atribuía a una exposición recurrente al fuego, lo que habría incrementado las várices, su eventual ruptura e infección.

Las lesiones articulares degenerativas se presentan aun en los individuos jóvenes. Estas son más frecuentes en varones que en mujeres, y la región más afectada es la cintura escapular. Existen diferencias significativas entre ambos grupos de sitios, presentándose la mayor prevalencia en los restos de ambos sexos del núcleo Gran Guaiteca. Considerando que la mayor frecuencia de lesiones articulares se relaciona con la región del hombro seguida del resto del miembro superior, se puede afirmar que ellas se vincularían con la boga, dada la importancia que esta actividad tenía en el grupo Chono (Fig. 10). Además, se denota un gran desarrollo de la musculatura flexora del tronco y de la aductora del muslo, grupos musculares de activa

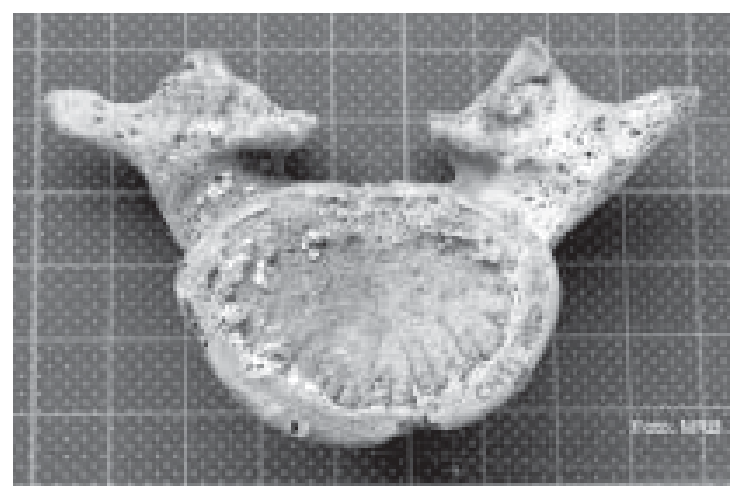

Fig. 12. Núcleo Gran Guaiteca - Repollal. Vista superior de vértebra lumbar de adulto de sexo masculino. Espondilolisis completa del arco neural. participación en la boga. Por otra parte, hay numerosas lesiones claviculares a nivel de la inserción del ligamento costo-clavicular (Fig. 11). Este conjunto de condiciones patológicas inducidas por actividad caracterizan a los grupos canoeros de la región fuego-patagónica y a otros grupos que practican intensamente la boga (Castro y Aspillaga 1991; Merbs 1983).

Es importante destacar la coincidencia en el tipo y frecuencia de las lesiones de columna entre los Chonos y las poblaciones Fueguinas. Nódulos de Schmorl, lesiones degenerativas y una elevada prevalencia de espóndilolisis de L4 y L5 (25\% en individuos del núcleo Gran Guaiteca) revelan el gran estrés al que estos individuos sometían sus troncos al cargar grandes pesos, como son la carga de presas, leña, las embarcaciones, entre otros (Fig. 12) (Constantinescu y Aspillaga 1991; Merbs 1996).

Finalmente, se evaluó la neumatización del hueso temporal como indicador indirecto de procesos infecciosos agudos durante la infancia. Se observó que el $64 \%$ de los individuos presentaba una neumatización alterada, lo que señalaría infecciones recurrentes del oído medio y por tanto exposición temprana a patógenos, dado que la neumatización de este hueso concluye hacia los 5 años. Igual porcentaje se observa en las tribus Fueguinas (Tabla 2) (Castro 2002).

\section{CONCLUSIONES}

L as condiciones patológicas observadas en los restos de aborígenes Chonos están vinculadas a su patrón de subsistencia. Los problemas articulares así como las entesopatías reflejan un modo de vida cazador recolector marino. Sin embargo, la elevada prevalencia de condiciones de carácter infeccioso y algunas lesiones de na- 
turaleza traumática señalarían que los Chonos eran un grupo en crisis adaptativa, situación que además se ve refrendada por un descenso en la demografía. Probablemente, esta crisis fue el resultado de la expansión de las poblaciones agricultoras del norte y más tardíamente de la creciente colonización europea.

\section{AGRADECIMIENTOS}

Agradecemos las recomendaciones entregadas por los revisores del trabajo. La incorporación de nuevos datos fue producto del Proyecto FONDECYT № 1020616 "Procesos y orígenes del poblamiento marítimo de los canales patagónicos: Chiloé y el núcleo septentrional".

\section{BIBLIOGRAFÍA}

ASPILLAGA, E.A., CASTRO, M.M. y OCAMPO, C.G. 1990. Paleopathology and life-style: the Chonoan and Fuegian examples (Abstract). American J ournal of Physical Anthropology, Supplement.

BULKELEY, J .y BYRON, J. (2004) The Loss of the Wager (The Narratives of J ohn Bulkeley and the Hon. J ohn Byron). Boydell Press. Londres.

BUTLAND, G.J . 1957. The Human Geography of Southern Chile. The Institute of British Geographers. Londres.

CAMPILLO, D. 1991. Aproximación metodológica a la paleopatología ósea. En: Nuevas Perspectivas en Antropología. Editado por M.C. Botella, S.A. J iménez, L. Ruiz y P.H. du Sovich, 107-130. Granada.

CASTRO, M.M. 2002. Palaeopathology of the Temporal Bone in Chilean Populations. Tesis de Doctorado. Uiversidad de Toronto. MS.

CASTRO, M.M. y ASPILLAGA, E.A. 1991. Fuegian paleopathology. Antropología Biológica 1: 1-13.

CONSTANTINESCU, F. y ASPILLAGA, E.A. 1991. Paleopatología de la columna vertebral en una muestra de indígenas Chonos. Actas del XI Congreso Nacional de Arqueología Chilena. Vol. III. MNHN y Sociedad Chilena de Arqueología, 237-241. Santiago.

COOPER, J.M. 1917. Analytical and Critical Bibliography of the Tribes of Tierra del Fuego and Adjacent Territory. Bureau of American Ethnology Bulletin 63. Smithsonian Institution. Washington, DC.

COOPER, J.M. 1946. The Chono. Handbook of South American Indians. Vol. 1: The Marginal Tribes. Editado
porJ. Steward. Bureau of American Ethnology Bulletin 143. Smithsonian Institution. Washington, DC.

DARWIN, C. 2001. The Voyage of the Beagle: J ournal of Researches into the Natural History and Geology of the Countries Visited During the Voyage of H.M.S. Beagle Round the World. Modern Library. New York.

HILLSON, S. 2000. Dental pathology. Biological Anthropology of the Human Skeleton. Editado por M.A. Katzenberg y S.R. Saunders, 249-286. Wiley-Liss. New York.

LINOSSIER, A., ASPILLAGA, E.A., GAJARDO, M. y OLAVARRIA, J.C. 1994. Paleomicrobiología oral en poblaciones de Chile: Chonos y Atacameños. Antropología Biológica 2(2): 63-73.

MENDONCA DE SOUZA, S.M.F., MAUL DE CARVALHO, D. y LESSA, A. 2003. Paleoepidemiology: is there a case to answer? Memorias del Instituto Oswaldo Cruz 98 (Suppl. 1): 21-27. Rio de J aneiro.

MERBS, C. 1983. Patterns of Activity-Induced Pathology in a Canadian Inuit Population. Archaeological Survey of Canada Paper 119. National Museums of Canada, Ottawa.

MERBS, C. 1996. Spondylolisis and pondilolisthesis: A cost of being erect biped or a clever adaptation? Yearbook of Physical Anthropology 39: 201-228.

OCAMPO, C.G. y ASPILLAGA, E.A. 1984. B reves notas sobre una prospección arqueológica en los archipiélagos de las Guaitecas y de los Chonos. Revista Chilena de Antropología 4:155.

ORTNER, D.J. 1992. Skeletal paleopathology. Probabilities, possibilities, and impossibilities. En: Disease and Demography in the Americas. Editado por J.W. Verano y D.H. Ubelaker, 5-13. Smithsonian Institution Press. Washington, DC.

ORTNER, D.J . 2003. Identification of Pathological Conditions in Human Skeletal Remains. San Diego, Academic Press.

QUINTANILLA, V. 1983. Biogeografía. Geografía de Chile, Vol. III. Instituto Geográfico Militar. Santiago.

QUIROZ, D. y OLIVARES, J.C. 1988. Nómades canoeros de la Patagonia O ccidental Insular Septentrional: El mundo de don Pedro del Agua. En: Encuentro de Etnohistoriadores. Editado por O. Silva, E. Medina y E. Téllez, 10-33. Universidad de Chile, Serie Nuevo Mundo: Cinco Siglos, № 1.

ROMERO, H. 1985. Geografía de los Climas. En: Geografía de Chile, Vol. XI. Instituto G eográfico Militar. Santiago.

UBELAKER, D.H. 1998. Ancient disease in anthropological context. En: Digging for Pathogens. Editado por C.L. Greenblatt, 175-199. Balaban Publishers. Rehovot.

URBINA, R. 1988. Los Chonos en Chiloé: Itinerario y aculturación. Chiloé 9: 29-42. 